\title{
A near $100 \%$ repair rate for mitral valve prolapse is achievable in a reference center: Implications for future guidelines
}

\author{
Javier G. Castillo, MD, Anelechi C. Anyanwu, MD, Valentin Fuster, MD, PhD, and David H. Adams, MD
}

\begin{abstract}
Background: Although mitral valve repair is the recommended treatment for severe mitral regurgitation of degenerative etiology, valve replacement remains common, particularly for complex lesions or anterior leaflet involvement. We sought to characterize the feasibility and outcomes of an "all comers" repair strategy applied systematically in all cases of degenerative mitral valve disease, regardless of age, complexity, or leaflet involvement.
\end{abstract}

\begin{abstract}
Methods: From January 2002 to December 2010, 744 consecutive patients (mean age, $58 \pm 13$ years [range, 12-90]; mean LVEF, 55\% $\pm 9 \%$ ) with degenerative mitral valve regurgitation and prolapse (anterior leaflet: $\mathrm{n}=42,6 \%$; posterior leaflet: $\mathrm{n}=556,75 \%$; bileaflet: $\mathrm{n}=146,19 \%$ ) underwent mitral valve surgery. Annular, leaflet or chordal calcification was present in $27 \%$ of cases.
\end{abstract}

Results: All patients underwent mitral valve repair and received a concomitant annuloplasty with a median ring size of $32 \mathrm{~mm}$ (interquartile range, 30-36). There was 1 early valve replacement ( $99.9 \%$ repair rate) due to atrioventricular groove bleeding and 5 late re-repairs $(0.7 \%)$ due to disease progression or infective endocarditis. In-hospital mortality and major stroke rates were $0.8 \%$ and $0.5 \%$, respectively. Survival rates at 1 and 5 years were $99.2 \% \pm 0.3 \%$ and $97.4 \% \pm 0.8 \%$, respectively. Seven-year freedom from reoperation was $97.1 \% \pm$ $0.6 \%$. The estimate of patients with $<3+$ mitral regurgitation at 4 and 7 years was $98 \%$ and $96 \%$, respectively, and $95 \%$ and $91 \%$, respectively, for $<2+$ mitral regurgitation.

Conclusions: A systematic strategy of mitral valve repair that uses a variety of techniques allows repair of all degenerative valves in a reference center, with good short-term outcomes and mid-term durability. Further study is required to document the long-term efficacy of an "all comers" mitral valve repair strategy in degenerative subgroups with very complex valve morphology. (J Thorac Cardiovasc Surg 2012;144:308-12)

Surgical mitral valve repair is the gold standard procedure for patients who require surgery for degenerative mitral valve regurgitation. The American College of Cardiology and American Heart Association guidelines for the management of patients with valvular heart disease suggest targeted referral to "reference centers" to ensure that a repair rate of at least $90 \%$ is achieved, especially those patients who are asymptomatic. ${ }^{1}$ Although simple posterior leaflet prolapse is associated with very high mitral valve repair rates in many centers, ${ }^{2,3}$ the overall repair rate for more complex scenarios, as defined by leaflet involvement (eg, anterior or bileaflet), ${ }^{4}$ lesion complexity (eg, significant annular calcification, giant excess tissue), or patient comorbidities (eg,

From the Department of Cardiothoracic Surgery, The Mount Sinai School of Medicine, New York, NY.

Disclosures: Dr Adams is co-inventor of the Carpentier Edwards Physio II ring and receives royalties from Edwards Lifesciences. The remaining authors have nothing to disclose with regard to commercial support.

Presented at The American Association for Thoracic Surgery Mitral Conclave, New York, New York, May 5-6, 2011.

Received for publication Aug 8, 2011; revisions received Nov 19, 2011; accepted for publication Dec 21, 2011; available ahead of print June 14, 2012.

Address for reprints: David H. Adams, MD, Department of Cardiothoracic Surgery, The Mount Sinai Medical Center, 1190 Fifth Ave, New York, NY 10029-102 (E-mail: david.adams@mountsinai.org).

0022-5223/\$36.00

Copyright $($ C 2012 by The American Association for Thoracic Surgery doi:10.1016/j.jtcvs.2011.12.054 older age, reoperations), ${ }^{5}$ remains less well established and appears to be well below the guidelines-recommended $90 \%$ threshold, at least partially explaining an average mitral valve repair rate of approximately $70 \%$ observed in the Society of Thoracic Surgeons database. ${ }^{6}$ We report our experience with a "repair for all comers" strategy in a consecutive series of patients referred for degenerative mitral repair surgery, regardless of lesion(s) or patient characteristics.

\section{MATERIALS AND METHODS}

\section{Study Population}

We retrospectively identified a total of 744 consecutive patients with degenerative mitral valve prolapse operated on for mitral regurgitation as the primary indication by a single surgeon (D.H.A.) and his team between January 2002 and December 2010. Degenerative mitral valve prolapse was confirmed in all patients by echocardiographic studies before the operative exploration. There were no exclusions for etiology of degenerative disease, such as Barlow disease or fibroelastic deficiency, or lesions, such as extensive annular calcification, chordal or papillary muscle scarring, or diffuse myxomatous degeneration. Of the 744 patients identified, $556(75 \%)$ had isolated posterior leaflet prolapse, $42(6 \%)$ had isolated anterior leaflet prolapse, and 146 (19\%) had bileaflet prolapse. Patient demographic characteristics, cardiac comorbidities, and other risk factors are summarized in Table 1. Mean patient age was $58 \pm 13$ years (range, 12-90) years. One hundred fifty-eight patients $(21 \%)$ were $\geq 70$ years old. Mean left ventricular ejection fraction was $55 \% \pm 9 \%$, and 91 patients $(12 \%)$ were in New York Heart Association functional class III or IV. Preoperative mitral regurgitation grade, as assessed semiquantitatively by echocardiography, was moderately severe in 48 patients $(6.5 \%)$ and severe in the remaining $696(93.5 \%)$. 
TABLE 1. Patient characteristics

\begin{tabular}{lc}
\hline Demographics & \\
Age (y, range) & $58 \pm 13(12-90)$ \\
Female (no.) & $263(35.3 \%)$ \\
Leaflet involvement (no.) & \\
Isolated posterior & $556(75 \%)$ \\
Isolated anterior & $42(6 \%)$ \\
Bileaflet & $146(19 \%)$ \\
Cardiac comorbidity & \\
LVEF (\%) & $55 \pm 9$ \\
Moderate to severe MR (no.) & $48(6.5 \%)$ \\
Severe MR (no.) & $696(93.5 \%)$ \\
Previous MI (no.) & $17(2.3 \%)$ \\
Previous sternotomy (no.) & $44(5.9 \%)$ \\
Previous mitral surgery (no.) & $18(2.4 \%)$ \\
Atrial fibrillation (no.) & $146(19.6 \%)$ \\
CAD (no.) & $80(10.8 \%)$ \\
\hline
\end{tabular}

$L V E F$, Left ventricular ejection fraction; $M R$, mitral regurgitation; $M I$, myocardial infarction, $C A D$, coronary artery disease.

\section{Surgical Technique}

Procedures were performed through a limited incision $(9-11 \mathrm{~cm})$ midline approach in most patients $(n=724 ; 97.3 \%)$. Standard cardiopulmonary bypass techniques were used with predominantly central cannulation. Direct aortic clamping and cardioplegic arrest was used in all cases, using cold blood cardioplegia given in an antegrade and retrograde fashion. Mild systemic hypothermia was used. All valves were accessed through a left atriotomy in the interatrial groove. Systematic valve analysis was undertaken to identify all lesions producing valve dysfunction(s).

Valve repairs were performed by means of standard reconstructive techniques (Table 2). ${ }^{7}$ Our typical approach was to sequentially repair the posterior leaflet, to perform a true-sized annuloplasty with a complete semirigid remodeling ring, and then to repair any residual prolapse of the anterior leaflet or commissures after inspection of the line of closure during testing with saline solution. We typically performed posterior leaflet repair by targeted resection (quadrangular or triangular) of any prolapsing segment, reducing the posterior annular dimension if appropriate and then

\section{TABLE 2. Reconstructive techniques}

\begin{tabular}{lc}
\hline AL resection (no.) & $29(3.9 \%)$ \\
PL resection (no.) & $633(85 \%)$ \\
$\quad$ Triangular & $139(21.9 \%)$ \\
$\quad$ Quadrangular & $479(78.1 \%)$ \\
Annular plication (no.) & $282(37.9 \%)$ \\
PL sliding plasty (no.) & $379(50.9 \%)$ \\
$\quad$ Limited & $162(42.7 \%)$ \\
$\quad$ Extensive & $183(48.2 \%)$ \\
$\quad$ Asymmetric & $34(9.1 \%)$ \\
PL shortening (no.) & $15(2.0 \%)$ \\
PL folding plasty (no.) & $13(1.7 \%)$ \\
Chordal transfer (no.) & $145(19.5 \%)$ \\
PTFE chordoplasty (no.) & $175(23.5 \%)$ \\
PL flip technique (no.) & $21(2.8 \%)$ \\
Loop technique (no.) & $16(2.2 \%)$ \\
Anterolateral CP (no.) & $33(4.3 \%)$ \\
Posteromedial CP (no.) & $92(12.3 \%)$ \\
Ring size (mm, IQR) & $32(30-36)$ \\
\hline$A L$, Anterior leaflet; $P L$, posterior leaflet; $P T F E$, polytetrafluoroethylene; $C P$, commi- \\
suroplasty; $I Q R$, interquartile range.
\end{tabular}

reconstructing the posterior leaflet. In the setting of excess posterior leaflet tissue, we typically performed a sliding leaflet plasty to reduce the height of the posterior leaflet to 1 to $1.5 \mathrm{~cm}$ in all segments. In valves with minimal tissue, the prolapse was corrected by limited triangular resections or insertion of artificial polytetrafluoroethylene chordae or loops or by native chordal transfer. Artificial chordae were also often used to reinforce the posterior leaflet resection repair or to displace further the closure line.

We corrected anterior leaflet prolapse primarily with polytetrafluoroethylene chordae or loops and chordal transfers, supplemented by triangular resection and commissural sutures in selected cases. A Carpentier-Edwards Physio I or II annuloplasty ring (Edwards Lifesciences LLC, Irvine, Calif) was used in $98 \%$ of the patients. Other annuloplasty devices, such as rigid or asymmetric rings, flexible posterior bands, and pericardial bands, were used for specific indications such as in pediatric cases and anomalous coronary anatomy. The ring size chosen was based on the surface area of the anterior mitral leaflet. Saline solution testing and intraoperative transesophageal echocardiography after weaning from cardiopulmonary bypass were performed in all patients to control for the quality of the repair.

\section{Predischarge Echocardiography}

Two-dimensional and Doppler transthoracic echocardiography examination was performed in all patients before discharge. All echocardiographic studies were performed by using commercially available $3.75-\mathrm{MHz}$ transducers and echocardiographic systems. Quantitative data promptly stored in the institutional server were not altered throughout the study.

The presence of mitral regurgitation was prospectively assessed and its severity was evaluated semiquantitatively by using the color Doppler regurgitant color jet area as previously validated. ${ }^{8}$ The grade of regurgitation was classified as none, trace (barely detected regurgitation), mild (jet area $<4 \mathrm{~cm}^{2}$ ), moderate (jet area, $4-10 \mathrm{~cm}^{2}$ ), and severe (jet area $>10 \mathrm{~cm}^{2}$ ).

\section{Data Collection}

Clinical variables were prospectively entered into the New York State Department of Health (State Cardiac Advisory Committee) data registry. The New York State Department of Health data registry represents a mandatory, verified, peer-reviewed data-collection system that includes all adult cardiac surgical procedures in the state of New York and records and analyzes data in a strictly supervised and widely reported fashion. Additionally, echocardiographic data, surgical pathology (etiology, location of lesions, leaflet integrity, annular characteristics, chordal distribution and degeneration, and integrity of the papillary muscles), and repair techniques were prospectively collected and entered into our departmental mitral database. Further information was obtained from patient records when necessary. Information regarding long-term survival was obtained by using the Web-based Social Security Death Index (last update May 2011). Complete follow-up information was available in $94 \%$ of the patients. The majority of patients lost to follow-up were international referrals. Echocardiography follow-up was performed by personal or telephone contact with the referring cardiologist. The protocol was approved by our local institutional review board and was compliant with the Health Insurance Portability and Accountability Act regulations and the ethical guidelines of the 1975 Declaration of Helsinki. The approval included a waiver of informed consent.

\section{Statistical Analysis}

Normally distributed continuous variables are represented as mean \pm standard deviation. Nonparametric and categoric variables are represented as median and interquartile range or as the number of patients as a percentage of the sample, respectively. Nonparametric survival was interrogated and analyzed by using Kaplan-Meier survival curves. Repair durability was obtained by echocardiographic follow-up. Mitral regurgitation grade over time was estimated by classical Kaplan-Meier techniques. Given the possibility of mitral regurgitation grade variation between follow-up 
echocardiograms, interval-censored curves were constructed by using an algorithm for nonparametric estimation. The statistical analyses were performed with the use of SPSS 19 (IBM Corp, Somers, NY).

\section{Statement of Responsibility}

All authors had full access to the data and take full responsibility for their integrity and accuracy. All authors have reviewed and agreed to the article as written.

\section{RESULTS}

Mitral valve repair was achieved in 743 patients $(99.9 \%)$. There was 1 mitral valve replacement in a 72 -year-old woman as the result of the presence of an atrioventricular groove hematoma recognized after weaning from bypass after mitral valve repair. The most commonly performed technique was posterior leaflet quadrangular resection $(n=479$; $64.3 \%$ ). Techniques frequently applied in conjunction with quadrangular resection were posterior leaflet sliding plasty $(\mathrm{n}=379 ; 79 \%)$ and annular plication $(\mathrm{n}=282 ; 59 \%)$. The predominant anterior leaflet techniques were use of polytetrafluoroethylene neochords and chordal transfer or posterior leaflet flip technique. All patients underwent a concomitant annuloplasty as part of the repair. Adjunct procedures included tricuspid valve repair in $62.5 \%$ of the patients, atrial fibrillation ablation therapy in $19.6 \%$, coronary artery bypass grafting in $10.8 \%$, and aortic valve surgery in $3.0 \%$. Any patient with more than trivial mitral regurgitation underwent reexploration during a second run on bypass, and this occurred in 20 cases $(2.7 \%)$.

Perioperative characteristics and outcomes are reported in Table 3. The overall in-hospital mortality rate was $0.8 \%(\mathrm{n}=6)$ and the overall 30-day mortality rate was $0.9 \%$ ( 1 patient died of an apparent arrhythmia while at home on day 13). Among patients younger than 70 years, the in-hospital mortality rate was $0.3 \%(n=2)$. Ninetytwo percent of the patients $(n=690)$ had a postoperative course with no major complications. Among those patients with postoperative complications, the 2 most common complications were respiratory failure $(\mathrm{n}=38 ; 5.1 \%)$ and overall stroke $(\mathrm{n}=12 ; 1.6 \%)$, defined as any new confirmed neurologic deficit, regardless of severity, that did not

TABLE 3. Operative details

\begin{tabular}{lc}
\hline Procedures & \\
Mitral valve repair & $743(99.9 \%)$ \\
Mitral valve replacement & $1(0.1 \%)$ \\
Concomitant procedures (no.) & \\
AF ablation therapy & $146(19.6 \%)$ \\
Tricuspid repair & $465(62.5 \%)$ \\
Aortic valve surgery & $22(3.0 \%)$ \\
CABG & $80(10.8 \%)$ \\
CPB time (min, IQR) & $181(147-230)$ \\
Aortic crossclamp time (min, IQR) & $144(118-191)$ \\
\hline$A F$, Atrial fibrillation; $C A B G$, coronary artery bypass grafting; $C P B$, cardiopulmo- \\
nary bypass; $I Q R$, interquartile range.
\end{tabular}

TABLE 4. Operative outcome

\begin{tabular}{lc}
\hline In-hospital mortality (no.) & $6(0.8 \%)$ \\
In-hospital mortality (no., age <70) & $2(0.3 \%)$ \\
Morbidity (no.) & \\
$\quad$ No major complications & $690(92.7 \%)$ \\
Major stroke & $4(0.5 \%)$ \\
Minor stroke & $8(1.1 \%)$ \\
Respiratory failure & $38(5.1 \%)$ \\
Renal failure & $5(0.7 \%)$ \\
Sternal wound infection & $5(0.7 \%)$ \\
Re-exploration for bleeding & $7(0.9 \%)$ \\
Sepsis & $8(1.1 \%)$ \\
Length of stay (d, IQR) & $6(5-8)$ \\
\hline
\end{tabular}

$I Q R$, Interquartile range.

resolve within 24 hours (www.health.ny.gov/statistics/ diseases/cardiovascular). When stroke was subdivided into major or minor on the basis of the presence of a permanent neurologic deficit, major stroke rate was $0.5 \%(\mathrm{n}=4)$. Detailed operative outcomes are reported in Table 4. The overall median hospital stay was 6 days (interquartile range, 5-8 days). Predischarge transthoracic echocardiography was performed in all patients. Six hundred ninety-seven patients $(94.5 \%)$ had no or trace mitral regurgitation, whereas 41 patients $(5.5 \%)$ had mild mitral regurgitation (Figure 1 ).

Overall estimated survival rate at 1 and 5 years was $99.2 \% \pm 0.3 \%$ and $97.4 \% \pm 0.8 \%$, respectively. The data compared equally with expected survival of the ageand gender-matched general population. Seven-year freedom from reoperation rate was $97.1 \% \pm 0.6 \%$. Five patients $(0.7 \%)$ required late reoperation for recurrent mitral valve regurgitation. Two of these patients required reintervention within the first year after surgery because of

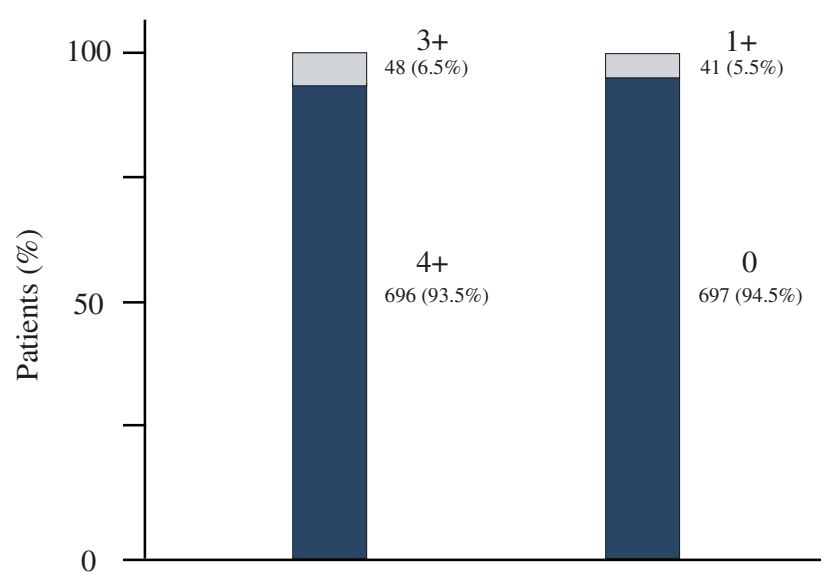

Preoperative TTE Predischarge TTE

Mitral Regurgitation Grade

FIGURE 1. Perioperative transthoracic echocardiographic (TTE) assessment. 0 , No mitral regurgitation (MR); $1+$, mild MR; $2+$, moderate MR; $3+$, moderate to severe MR; $4+$, severe MR. 


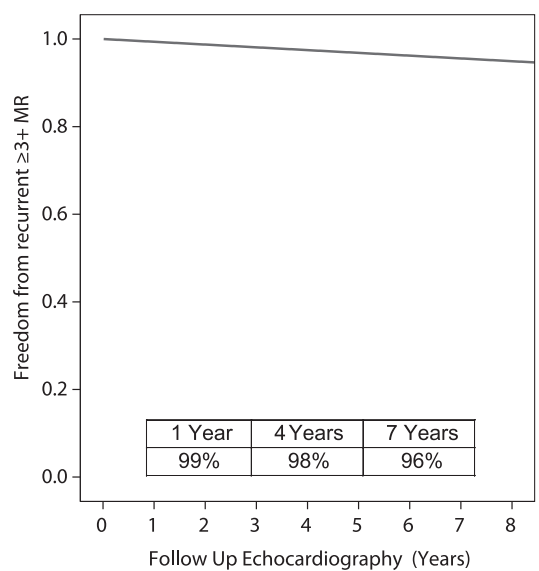

A

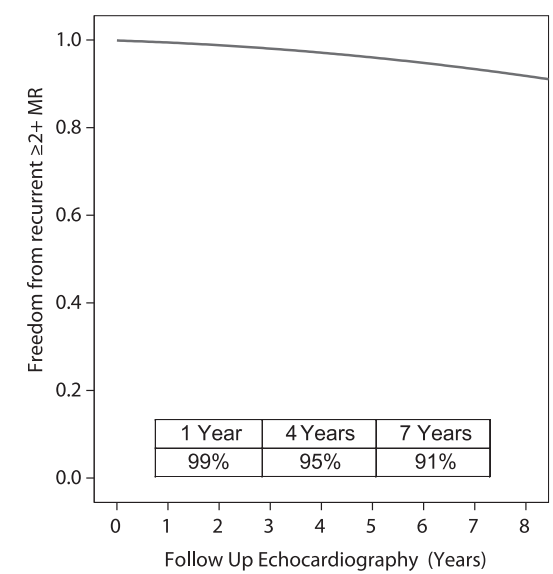

B

FIGURE 2. Estimated freedoms from (A) recurrent moderate to severe or severe ( $\geq 3+$ ) mitral regurgitation $(M R)$ and (B) moderate ( $\geq 2+)$ mitral regurgitation. 0, No MR; 1+, mild MR; 2+, moderate MR; 3+, moderate to severe MR; 4+, severe MR.

acute bacterial endocarditis and 3 patients 3 and 5 years after surgery because of progression of degenerative valve disease (all of these patients were re-repaired). All surviving patients underwent a postoperative transthoracic echocardiographic study, and late follow-up echocardiography was available in $70 \%$ of the patients. Mean echocardiography follow-up time was $1.5 \pm 1.1$ years (range, 7-2527 days). Among those patients having follow-up echocardiograms, the estimate of patients with less than moderate-tosevere or severe mitral regurgitation grades at 4 and 7 years was $98 \%$ and $96 \%$, respectively, versus $95 \%$ and $91 \%$, respectively, for less than moderate mitral regurgitation (Figure 2).

\section{DISCUSSION}

We have demonstrated that it is possible to repair practically all prolapsing degenerative mitral valves, with a low surgical risk and absence of residual significant mitral regurgitation in a high-volume reference center. Our study is unique because we have not selected patients and have applied mitral valve repair to all comers regardless of complexity of valve disease, patient age or comorbidity, and perceived surgical risk. Most large series of contemporary mitral valve surgery for degenerative disease in reference centers have reported a valve replacement rate of up to $5 \%$ to $10 \%,{ }^{9}$ with preferential use of valve replacement in higher-risk groups, such as elderly patients, ${ }^{5}$ or for more complex valve pathology, including bileaflet prolapse. ${ }^{4}$ Although other series have also shown repair rates nearing $100 \%$, those series have been limited to a selected group with posterior leaflet prolapse. ${ }^{3}$ Although the superiority of repair relative to replacement remains controversial for certain high-risk subsets, we have shown that with a systematic approach it is possible to repair all degenerative valves with low operative risk and good immediate result.
Our mortality of less than $1 \%$, with $92 \%$ of patients discharged from the hospital without any major complications, the absence of residual mitral regurgitation, and a repair rate of $99 \%$ in our study satisfy the 3 key essentials for a reference mitral valve repair program, as stipulated by the American College of Cardiology and American Heart Association guidelines. ${ }^{1}$ As more and more asymptomatic patients are referred for surgery, it becomes imperative that we can reasonably assure a repair at minimal risk and with good immediate results. Our data suggest that such a goal is achievable with a systematic strategy of repair of all valves by a highly specialized valve team that includes anesthesiologists, intensivists, and cardiologists.

Our results must be interpreted with certain clarifications or caveats in mind, some of which may limit extrapolation and reproducibility. First, ours is a high-volume mitral valve reference center, and this series represents a single surgeon's highly specialized team results. Second, the vast majority of cases were done through a limited midline approach because our prime focus has always been on optimal access to allow application of any reconstructive technique to achieve a successful repair. Third, we have not used a single technique to repair all valves. We do not subscribe to the "resect or respect" philosophies ${ }^{10-12}$; rather, we adapt our technique to the lesions seen in each valve, applying both resectional and nonresectional techniques. We believe that using a blend of techniques, rather than a single approach, is essential if the goal is to repair all degenerative valves. Fourth, we will take as long as necessary to repair a valve; a quarter of our patients had crossclamp times in excess of 3 hours. Some complex valve scenarios, such as reoperative repair and repair in patients with advanced Barlow disease or mitral annular calcification, require prolonged periods of aortic crossclamping to affect repair. Thus, to achieve a $100 \%$ repair rate, one must be prepared to accept the occasional 
long clamp time. Fifth, we rarely accept any degree of residual mitral regurgitation, other than trivial, on postbypass transesophageal echocardiography. If there is even mild regurgitation, then we almost always put the patient back on bypass and perfect the repair. Finally, we believe strongly in a lesion-based approach to mitral valve repair and in differentiation of degenerative etiologies, ${ }^{13}$ and we hold that the key to affecting the ideal repair is tailoring of techniques to lesions and etiology.

Our outcome data is similar to other large series in terms of freedom from reoperation and recurrence of significant mitral regurgitation. ${ }^{2,5,9,14-19}$ This is significant in that we used a "repair all comers" strategy (which was not the case in all of the series describing long-term echocardiographic data), and there was no selection of patients based on lesion complexity, which may have negatively impacted durability. ${ }^{18}$ Although our study was retrospective, such a study method would not have an effect on our key findings. Finally, because ours is a reference center, there may be referral bias, and our patients may not be typical of those seen in other centers. Our observation, however, is that as a national reference center, although our institution may attract substantial number of patients with early disease, it also attracts a considerable number with advanced pathology. For example, 18 patients $(2.4 \%)$ had undergone previous mitral valve surgery for prolapse and required reoperative valve repair.

We have shown that, with a systematic approach, almost all degenerative mitral valves can be repaired safely with excellent early results. We believe that as a specialty we should aspire to such a goal, arguably for all patients but especially for the asymptomatic cohort. We do understand that there is a definite volume-outcome relationship within mitral valve surgery, ${ }^{20}$ such that these goals, although likely now achievable in most reference centers, would be unrealistic for most surgeons who do few mitral valve repairs. Our data, therefore, add additional emphasis to the guideline recommendation to refer patients with mitral valve prolapse to specialized reference surgical centers if there is a doubt about the probability of repair in a particular patient. ${ }^{1}$ Our data also adds to the debate as to whether volume, performance, and outcome criteria should be used to designate a minimum standard for centers undertaking degenerative mitral valve repair, ${ }^{21}$ particularly in young or asymptomatic patients in the future. ${ }^{22,23}$

\section{References}

1. Bonow RO, Carabello BA, Chatterjee K, de Leon AC Jr, Faxon DP, Freed MD, et al. 2008 focused update incorporated into the ACC/AHA 2006 guidelines for the management of patients with valvular heart disease: a report of the American College of Cardiology/American Heart Association Task Force on Practice Guidelines (Writing Committee to revise the 1998 guidelines for the management of patients with valvular heart disease). Endorsed by the Society of Cardiovascular Anesthesiologists, Society for Cardiovascular Angiography and
Interventions, and Society Of Thoracic Surgeons. J Am Coll Cardiol. 2008;52: e1-142.

2. Johnston DR, Gillinov AM, Blackstone EH, Griffin B, Stewart W, Sabik JF III, et al. Surgical repair of posterior mitral valve prolapse: Implications for guidelines and percutaneous repair. Ann Thorac Surg. 2010;89:1385-94.

3. Mihaljevic T, Jarrett CM, Gillinov AM, Williams SJ, DeVilliers PA, Stewart WJ, et al. Robotic repair of posterior mitral valve prolapse versus conventional approaches: potential realized. J Thorac Cardiovasc Surg. 2011;141:72-80.e1-4.

4. Umakanthan R, Leacche M, Petracek MR, Kumar S, Solenkova NV, Kaiser CA, et al. Safety of minimally invasive mitral valve surgery without aortic crossclamp. Ann Thorac Surg. 2008;85:1544-50.

5. Gillinov AM, Blackstone EH, Alaulaqi A, Sabik JF III, Mihaljevic T, Svensson LG, et al. Outcomes after repair of the anterior mitral leaflet for degenerative disease. Ann Thorac Surg. 2008;86:708-17.

6. Gammie JS, Zhao Y, Peterson ED, O'Brien SM, Rankin JS, Griffith BP. J. Maxwell Chamberlain Memorial Paper for adult cardiac surgery. Less-invasive mitral valve operations: trends and outcomes from the Society of Thoracic Surgeons Adult Cardiac Surgery Database. Ann Thorac Surg. 2010;90: 1401-10, 1410.e1.

7. Carpentier AC, Adams DH, Filsoufi F. Carpentier's reconstructive valve surgery. Maryland Heights (MO): Saunders; 2010.

8. Zoghbi WA, Enriquez-Sarano M, Foster E, Grayburn PA, Kraft CD, Levine RA, et al. Recommendations for evaluation of the severity of native valvular regurgitation with two-dimensional and doppler echocardiography. J Am Soc Echocardiogr. 2003; 16:777-802.

9. Seeburger J, Borger MA, Doll N, Walther T, Passage J, Falk V, et al. Comparison of outcomes of minimally invasive mitral valve surgery for posterior, anterior and bileaflet prolapse. Eur J Cardiothorac Surg. 2009;36:532-8.

10. Falk V, Seeburger J, Czesla M, Borger MA, Willige J, Kuntze T, et al. How does the use of polytetrafluoroethylene neochordae for posterior mitral valve prolapse (loop technique) compare with leaflet resection? A prospective randomized trial. J Thorac Cardiovasc Surg. 2008;136:1205-6.

11. Lawrie GM, Earle EA, Earle NR. Nonresectional repair of the barlow mitral valve: importance of dynamic annular evaluation. Ann Thorac Surg. 2009;88: 1191-6.

12. Seeburger J, Falk V, Borger MA, Passage J, Walther T, Doll N, et al. Chordae replacement versus resection for repair of isolated posterior mitral leaflet prolapse: a egalite. Ann Thorac Surg. 2009;87:1715-20.

13. Adams DH, Anyanwu AC. Seeking a higher standard for degenerative mitral valve repair: Begin with etiology. J Thorac Cardiovasc Surg. 2008;136: 551-6.

14. Braunberger E, Deloche A, Berrebi A, Abdallah F, Celestin JA, Meimoun P, et al. Very long-term results (more than 20 years) of valve repair with carpentier's techniques in nonrheumatic mitral valve insufficiency. Circulation. 2001;104: I8-11.

15. Brown ML, Schaff HV, Li Z, Suri RM, Daly RC, Orszulak TA. Results of mitral valve annuloplasty with a standard-sized posterior band: Is measuring important? J Thorac Cardiovasc Surg. 2009;138:886-91.

16. David TE, Ivanov J, Armstrong S, Christie D, Rakowski H. A comparison of outcomes of mitral valve repair for degenerative disease with posterior, anterior, and bileaflet prolapse. J Thorac Cardiovasc Surg. 2005;130:1242-9.

17. DiBardino DJ, ElBardissi AW, McClure RS, Razo-Vasquez OA, Kelly NE, Cohn LH. Four decades of experience with mitral valve repair: Analysis of differential indications, technical evolution, and long-term outcome. J Thorac Cardiovasc Surg. 2010;139:76-83.

18. Flameng W, Meuris B, Herijgers P, Herregods MC. Durability of mitral valve repair in barlow disease versus fibroelastic deficiency. $J$ Thorac Cardiovasc Surg. 2008; 135:274-82.

19. Gillinov AM, Blackstone EH, Nowicki ER, Slisatkorn W, Al-Dossari G, Johnston DR, et al. Valve repair versus valve replacement for degenerative mitral valve disease. J Thorac Cardiovasc Surg. 2008;135:885-93. 893.e2.

20. Bolling SF, Li S, O'Brien SM, Brennan JM, Prager RL, Gammie JS. Predictors of mitral valve repair: clinical and surgeon factors. Ann Thorac Surg. 2010;90: 1904-12.

21. Bridgewater B, Hooper T, Munsch C, Hunter S, von Oppell U, Livesey S, et al. Mitral repair best practice: Proposed standards. Heart. 2006;92:939-44.

22. Adams DH, Anyanwu AC. The cardiologist's role in increasing the rate of mitral valve repair in degenerative disease. Curr Opin Cardiol. 2008;23:105-10.

23. Adams DH, Rosenhek R, Falk V. Degenerative mitral valve regurgitation: best practice revolution. Eur Heart J. 2010;31:1958-66. 